\title{
Experimental and theoretical study on corrosion inhibition of new synthesized menthone derivatives (Menthopyrazole compounds) for mild steel in $1 \mathrm{M} \mathrm{HCl}$ solution
}

\author{
Abdeslam Ansari ${ }^{1, *}$, Mounir Manssouri ${ }^{2}$, Amal Laghchimi ${ }^{2}$, Mohamed Znini ${ }^{2}$, Zouhair Lakbaibi ${ }^{3}$ \\ and Mohamed Azrour ${ }^{1}$ \\ ${ }^{1}$ Université My Ismail, Laboratoire de Chimie Physique des Matériaux, Faculté des Sciences et Techniques, \\ Po Box 509, Errachidia, Morocco \\ ${ }^{2}$ Université My Ismail, Laboratoire des Substances Naturelles \& Synthèse et Dynamique Moléculaire, Faculté \\ des Sciences et Techniques, Po Box 509, 52003, Errachidia, Morocco. \\ ${ }^{3}$ Université My Ismail, Département de Chimie, Faculté des Sciences et Techniques, Po Box 509, 52003, \\ Errachidia, Morocco.
}

\begin{abstract}
The aim of the present work is to evaluate the protective ability of newly menthone derivatives 7-isopropyl-4-methyl-4,5,6,7-tetrahydro-1H-indazole (HMP) and 7-isopropyl-4-methyl-1-phenyl-4,5,6,7tetrahydro-1H-indazole (PMP) as mild steel corrosion inhibitors in $1 \mathrm{M} \mathrm{HCl}$, which may get applications as ecofriendly corrosion inhibitors in acidizing processes in the industry. The corrosion attitude of mild steel at various concentrations of the inhibitors was examined in the range from 298 to $328 \mathrm{~K}$. An increase in the inhibitory effectiveness in acidic solution at higher concentration and temperature follow the existence of inhibitors. The aspect of adsorption mixed type of inhibitors was highlighted by the Polarization curves. The adsorption of HMP and PMP is in line with the Langmuir isotherm model. Theoretical indices study of both inhibitors (HMP and PMP) via CDFT (the conceptual density functional theory) has been studied. To search for the best spatial configuration of steel/inhibitor a Monte Carlo simulation studies were applied.
\end{abstract}

Keywords: Menthone derivatives, Mild steel, Corrosion inhibition, Adsorption, Density functional theory (CDFT).

\section{Introduction}

Industries and machinery are widely based on mild steel. However, acids such as sulfuric and hydrochloric acids used in the pickling process of metals cause its deterioration ${ }^{1,2}$. Thus, serious efforts are being made to stop or delay to the maximum the attack of this metal in various corrosive media. Generally, the organic compounds typically contain oxygen or nitrogen heteroatoms in a conjugated system, are known be applicable as corrosion inhibitors for steel in acidic media ${ }^{3}$. Therefore, it is possible to suggest that the presence of heteroatoms facilitates the adsorption of their molecules onto the surface, thereby reducing the corrosion rate in acidic solutions. The inhibition properties in the acidic medium of these compounds can be attributed to the number of mobile electrons pair present, the $\pi$ orbital character of free electrons and the electron density around nitrogen and oxygen atoms ${ }^{4-6}$. Due to the inimical effect of some chemicals, research activities

*Corresponding author: Abdeslam Ansari

Email address: ansdesa2@yahoo.fr

DOI: http://dx.doi.org/10.13171/mjc101020291189aa in recent times are towards developing cheap, nontoxic and environmentally safe corrosion inhibitors low-cost ${ }^{7-9}$. In this perspective, previous studies in our laboratory reported that monoterpenoid ketones derived from $\mathrm{p}$-menthane have a wide spectrum of anticorrosive activities ${ }^{10,11}$, carvone derivatives and dihydrocarvone derivatives ${ }^{12,13}$ possess corrosioninhibiting properties. In continuation of our work on the development of p-menthane derivatives as hydrochloric acid inhibitors of steel, we have studied, more recently, the acid inhibiting steel corrosion behavior of menthone ${ }^{14}$. The encouraging results obtained by this ketone as acid inhibitor has invited us to investigate for such application two synthesized menthone derivatives, namely 7-isopropyl-4-methyl4,5,6,7-tetrahydro-1H-indazole (HMP) and 7-isopropyl-4-methyl-1-phenyl-4,5,6,7-tetrahydro1H-indazole (PMP), utilizing the same technics and experimental condition. Their chemical structure appears in Table 1. The kinetics of corrosion, together with the adsorption process, was explained by varying

Received November 27, 2019 Accepted December 21, 2020 Published January 30, 2020 
temperature and concentration of each inhibitor and then the thermodynamic parameters were evaluated and discussed. Lately, density functional theory (DFT) ${ }^{15}$ has become very useful in determining the molecule's properties. This method has a conjoint practice to calculate quantum chemical corrosion. The study is about to evaluate the protective effect ability of PMP and HMP as corrosion inhibitors. In this paper computational parameters were discussed. This was done by using theoretical indices defined in CDFT (the conceptual density functional theory) with the correlation-exchange functional (B3LYP) ${ }^{16}$ on the basis $6-31 \mathrm{G}(\mathrm{d}, \mathrm{p})^{17}$ level set in the gas phase. Finally, Monte Carlo studies (MC) were engaged to show the best configurational space of the iron/menthone derivative system.

Table 1. Structures of the two menthone derivatives investigated as corrosion inhibitors in hydrochloric acid

\begin{tabular}{|c|c|c|}
\hline Code & Name & Structure \\
\hline HMP & 7-isopropyl-4-methyl-4,5,6,7-tetrahydro- \\
& 1H-indazole & \\
\hline PMP & 7-isopropyl-4-methyl-1-phenyl-4,5,6,7-tetrahydro- \\
& 1H-indazole & \\
\hline
\end{tabular}

\section{Experimental}

\subsection{Synthesis and characterizationof inhibitors}

The preparation of 7-isopropyl-4-methyl-4,5,6,7tetrahydro-1H-indazole (HMP) and 7-isopropyl-4methyl-1-phenyl-4,5,6,7-tetrahydro-1H-indazole (PMP) was done according to the operating procedure described in our previous work ${ }^{18}$.

\subsection{Weight loss measurements}

The material used in this work is C38 carbon steel. The surface of steel coupons chosen is $(2 \mathrm{~cm} \times 2 \mathrm{~cm})$ and the corrosive medium is $1 \mathrm{~mol} \mathrm{~L}^{-1} \mathrm{HCl}$, obtained from the commercial solution of $\mathrm{HCl}(37 \%)$ with distilled water. For weight loss Measurements, weighing of the Mild-steel coupons was done beforehand and post immersion in the $10 \mathrm{ml}$ corrosive solution for $6 \mathrm{hrs}$. The speed of corrosion $W\left(\mathrm{mg} \mathrm{cm}^{-2} \mathrm{~h}^{-1}\right)$, efficiency $E w(\%)$ were calculated according to the Eqs. (1) and (2) respectively ${ }^{19}$ :

$$
\begin{aligned}
& \mathrm{W}=\frac{\Delta \mathrm{m}}{\mathrm{St}} \\
& \mathrm{E}_{\mathrm{W}} \%=\frac{\mathrm{Wcorr}-\mathrm{Wcorr}(\mathrm{inh})}{\mathrm{Wcorr}} \times 100
\end{aligned}
$$

Where $\Delta \mathrm{m}(\mathrm{mg})$ is the specimen weight before and after immersion in the tested solution, $W_{\text {corr }}$ and $\mathrm{W}_{\text {corr(inh) }}$ are the values of corrosion weight losses $\left(\mathrm{mg} / \mathrm{cm}^{2} . \mathrm{h}\right)$ of mild steel in uninhibited and inhibited solutions, respectively, $\mathrm{S}$ is the area of the mild steel specimen $\left(\mathrm{cm}^{2}\right)$ and $\mathrm{t}$ is the exposure time $(\mathrm{h})$.

\subsection{Electrochemical studies}

The electrochemical measurements were carried out by means of a conventional three-electrode electrolysis cylindrical Pyrex glass cell. The working electrode from $\mathrm{C} 28$ steel has a geometric area of $1 \mathrm{~cm}^{2}$; a saturated $\mathrm{Ag} / \mathrm{AgCl}$ electrode and a disc platinum electrode were used as against (CE) electrodes. The inhibition efficiency $(E I \%)$ was defined by equation (3):
EI $\%=\frac{\text { Icorr }- \text { Icorr }(\text { inh })}{\text { Icorr }} \times 100$

Where Icorr and Icorr (inh) are the corrosion current density values with and without the inhibitor, respectively, obtained by extrapolation of cathodic and anodic Tafel lines to the corrosion potential.

Electrochemical impedance spectroscopy measurements were achieved at the open circuit potential for the frequency range of $100 \mathrm{KHz}$ to $10 \mathrm{mHz}$, using a peak-to-peak voltage excitation of $10 \mathrm{mV}$. The inhibition efficiency got from the chargetransfer resistance is calculated by the following relation:

$E R t \%=\frac{R^{\prime} t-R t}{R^{\prime} t} \times 100$

Where $R_{t}$ and $R_{t}$, are the charge-transfer resistance values without and with inhibitor respectively. $R_{t}$ is the diameter of the loop.

\subsection{Quantum chemical calculation}

The optimized geometry of the HMP and PMP was performed utilizing DFT method ${ }^{20,21}$ using program Gaussian 0922 in the scheme of B3LYP hybrid functional ${ }^{16}$ with the $6-31 \mathrm{G}(\mathrm{d}, \mathrm{p})$ basis set ${ }^{23}$ Then, the local electrophilic, $\mathrm{P}^{+}$, and nucleophilic, $\mathrm{P}^{-}$, Parr functions ${ }^{24}$ are obtained from the analysis of the Mulliken atomic spin density 17 (ASD) at the radical anion and the radical cation by adding and removing an electron to the studied inhibitor, respectively. Quantum parameters, such as the dipolar moment $(\mu)$, EHOMO, ELUMO, energy gap $(\Delta \mathrm{E})$, ionization potential (I), electronic affinity (A), hardness $(\eta)$, electronegativity $(\chi)$, electrophilia $(\omega)$ and softness (S) have been computed ${ }^{20}$. For Monte Carlo simulations (MC) and RDF simulations ${ }^{25,26}$, the iron surface (110) is built in Biovia Materials studio 8.0 27 as follows: slab thickness of $15 \AA$, a supercell of $(10 * 10)$ and a vacuum of $25 \AA$ along the ox, oy and oz 
axis in a simulation box $\mathrm{Fe}(110)(24.82 \times 24.82 \times 40 \AA)$ with periodic boundary conditions to model a representative part of the interface devoid of any arbitrary boundary effects 13,19 . The build surface of Fe (110) is optimized using molecular mechanics. Moreover, the complete MC simulation goals to study alignment and adsorption behavior in tow environments: firstly, in vacuum (one molecule of PMP or HMP and Fe(110) surface) and secondly, in solution (one molecule of PMP or HMP, 500 molecules of water and $\mathrm{Fe}(110)$ surface) using COMPASS (Condensed-phase Optimized Molecular Potentials for Atomistic Simulation Studies) force field ${ }^{28}$ by means the adsorption locator module integrating in Biovia Materials studio version 8.0. The adsorption behavior was evaluated through Radial Distribution Function (RDF) analysis using the Forcite calculation code ${ }^{29}$.

\section{Results and Discussion}

\subsection{Potentiodynamic polarization curves}

Potentiodynamic polarization of mild steel specimens in the studded electrolyte without and with corrosion inhibitors at $308 \mathrm{~K}$ are shown in Fig.1 and 2. The respective kinetic parameters such as $I_{\text {corr }}$ (corrosion current density), $E_{c o r r}$ (corrosion potential), $\beta_{c}$ (cathodic slopes) and $I E \%$ (inhibition efficiency) are listed in Table 2.

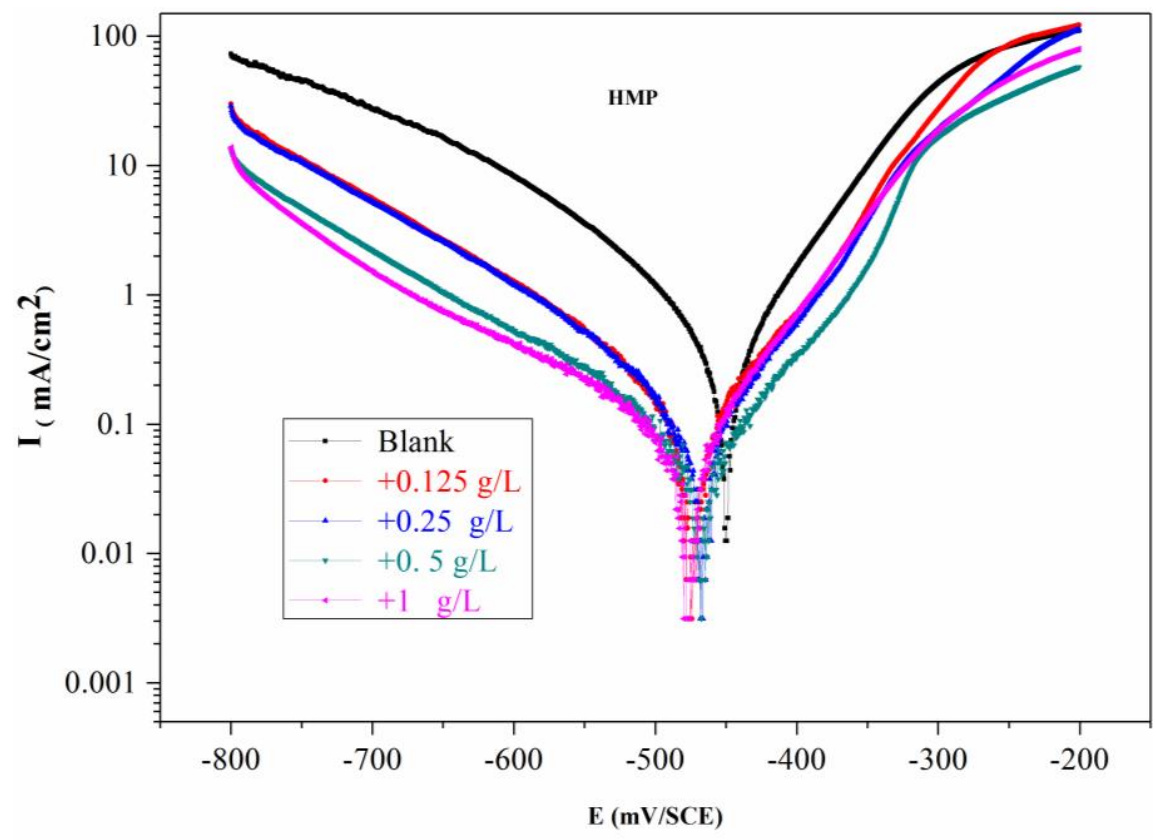

Figure 1. Anodic and cathodic polarization curves of mild steel in solutions of $1 \mathrm{M} \mathrm{HCl}$ without and with different concentrations of HMP

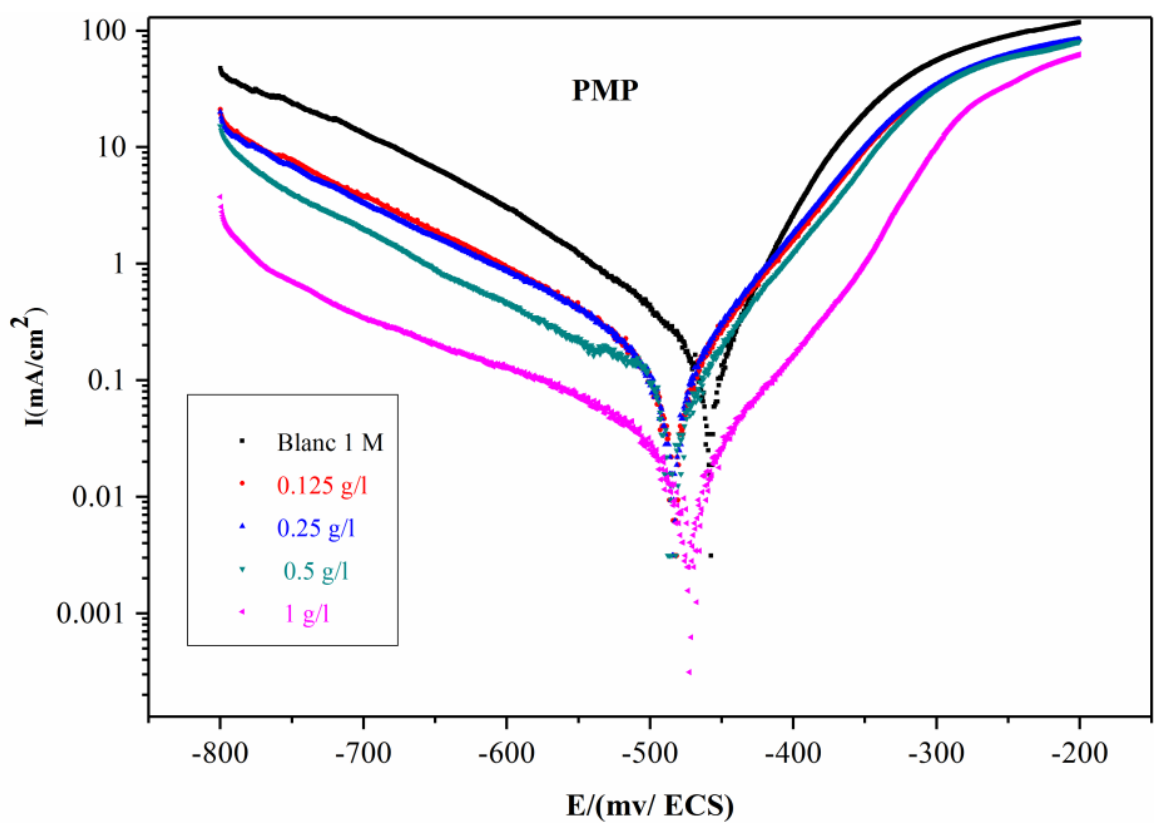

Figure.2 Anodic and cathodic polarization curves of mild steel in solutions of $1 \mathrm{M} \mathrm{HCl}$ without and with different concentrations of PMP 
Table 2. Electrochemical parameters of steel at different concentrations of $\mathbf{H M P}$ and $\mathbf{P M P}$ studied in $1 \mathrm{M} \mathrm{HCl}$ at $308 \mathrm{~K}$.

\begin{tabular}{|c|c|c|c|c|c|}
\hline Inhibitor & $\mathrm{C}\left(\mathrm{g} \mathrm{L}^{-1}\right)$ & $-\mathrm{E}_{\text {corr }}(\mathrm{mV})$ & $\mathrm{I}_{\text {corr }}\left(\mathrm{mA} \mathrm{cm} \mathrm{cm}^{-2}\right)$ & $-\beta_{\mathrm{c}}\left(\mathrm{mV} \mathrm{dec}{ }^{-1}\right)$ & $\mathrm{E}_{\mathrm{I}}(\%)$ \\
\hline \multirow{5}{*}{ HМP } & Blank & 450 & 0.420 & 105 & ------- \\
\hline & 0.125 & 475 & 0.236 & 166 & 44.8 \\
\hline & 0.25 & 412 & 0.111 & 120 & 73.6 \\
\hline & 0.5 & 467 & 0.068 & 153 & 83.9 \\
\hline & 1 & 448 & 0.046 & 132 & 89.0 \\
\hline \multirow{4}{*}{ PMP } & 0.125 & 484 & 0.179 & 163 & 43.0 \\
\hline & 0.25 & 485 & 0.170 & 165 & 60.0 \\
\hline & 0.5 & 487 & 0.062 & 141 & 85.2 \\
\hline & 1 & 473 & 0.014 & 156 & 96.6 \\
\hline
\end{tabular}

Examination of the Figures. 1 and 2 shows a modification of the mechanism of cathodic hydrogen reduction as well as anodic dissolution, which suggests that the addition of inhibitors reduce the corrosion process, at the same times data in Table 2 proved that the corrosion with current densities $\left(I_{c o r r}\right)$ decreases remarkably by increasing HMP and PMP concentration. Consequently, the inhibition efficiency $(I E \%)$ increases reaching its maximum values 89 and 96.6 $\%$ at $1 \mathrm{~g} / \mathrm{L}$ for the HMP and PMP respectively. This increase marked in the case of PMP is presumably because the benzene ring which gives him more electron density so more able to be adsorbed on the surface of the steel ${ }^{30}$. By the addition of inhibitors, a modest shift of corrosion potential toward the negative values compared to those in the uninhibited solution was induced. The maximum displacement in $E_{\text {corr }}$ value was $34 \mathrm{mV}$ for PMP and $25 \mathrm{mV}$ for HMP which suggests that the inhibitors performing as a mixed type of inhibitor with main control of cathodic reaction ${ }^{31,32}$.

\subsection{Electrochemical impedance spectroscopy (EIS)}

The corrosion process of mild in hydrochloric acid with inhibitors HMP and PMP was investigated by $(E I S)$ at $308 \mathrm{~K}$ after an exposure period of $30 \mathrm{~min}$.

Nyquist plots of steel in $1 \mathrm{M} \mathrm{HCl}$ containing $\mathbf{H M P}$ and PMP at various concentrations are given in Figs. 3 and 4.

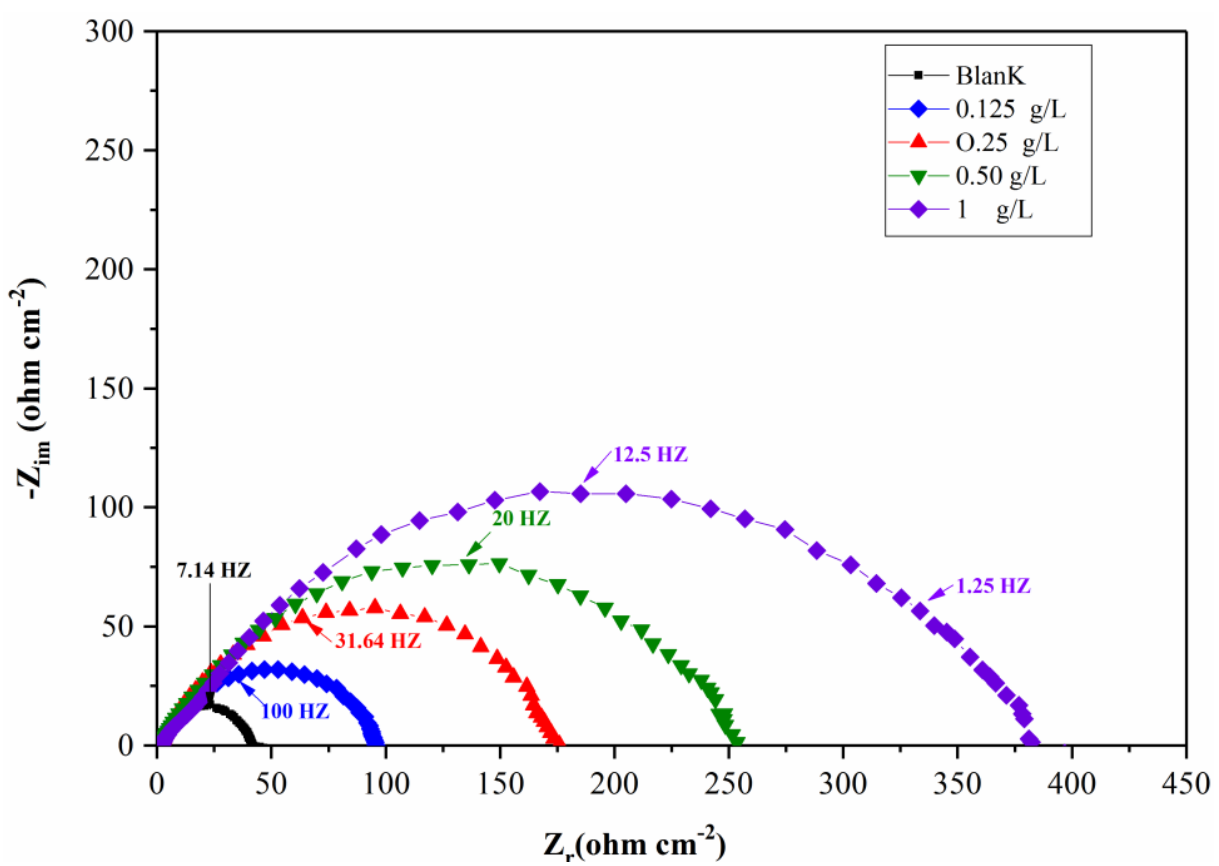

Figure 3. Nyquist plots for mild steel in $1 \mathrm{M} \mathrm{HCl}$ without and with different concentrations of $\mathbf{H M P}$ 


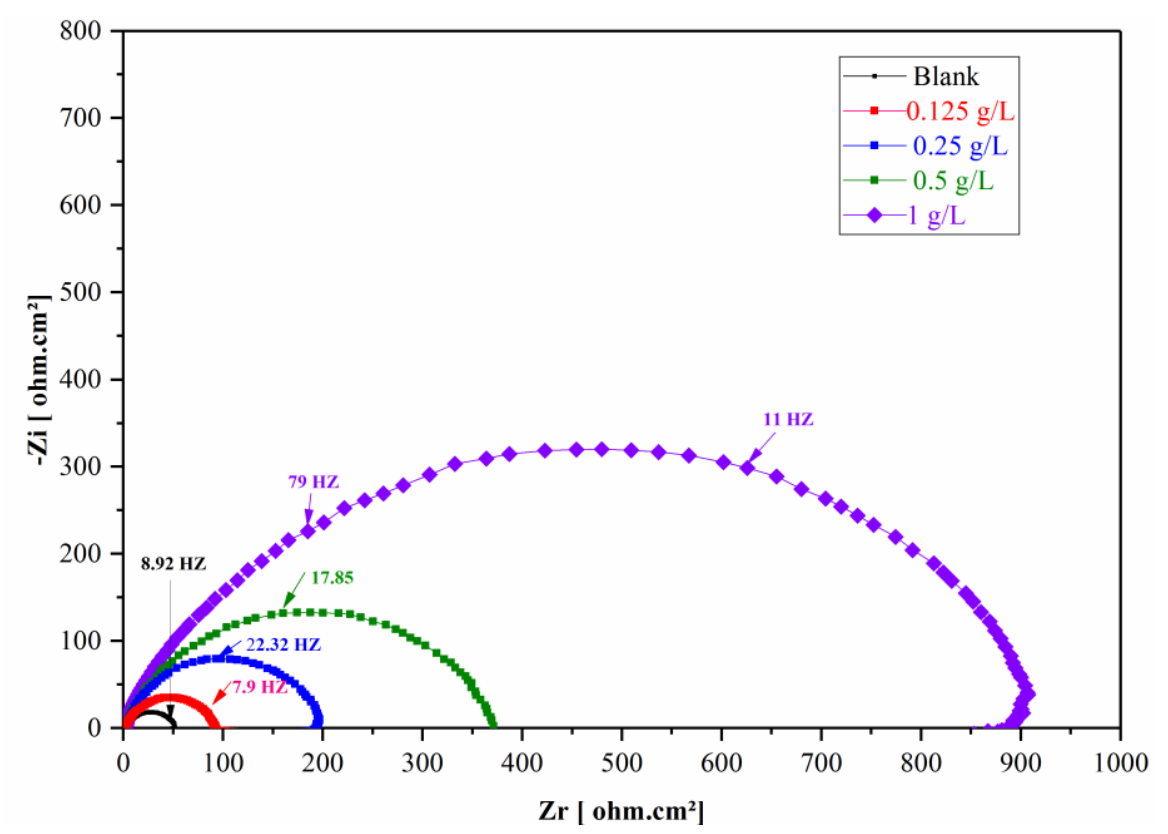

Figure 4. Nyquist plots for mild steel in $1 \mathrm{M} \mathrm{HCl}$ without and with different concentrations of PMP

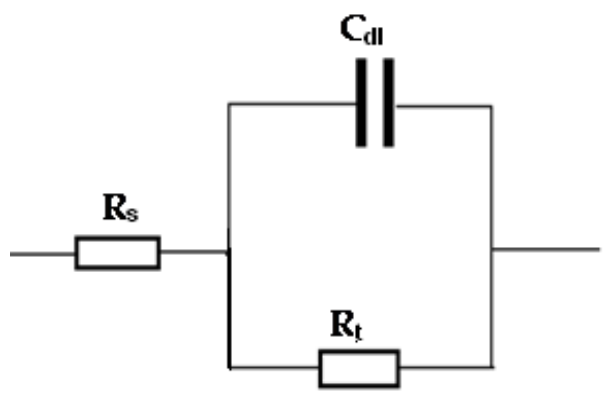

Figure 5. Equivalent circuit used to fit the electrochemical impedance spectroscopy (EIS) data

As we noted, the impedance spectra (Figs.3 and 4) dispose of a unique capacitive loop. This unique capacitive loop indicating that the only process occurring is charge transfer ${ }^{33,34}$. Furthermore, these capacitive loops are not the perfect semicircles due to a frequency dispersion effect ${ }^{35}$ From the resulting data on impedance (Table 3) PMP found to be the best inhibitor. Indeed, an increase in the value of $R_{t}$ in acidic solution and higher efficiencies in inhibition follow the existence of inhibitors. The decrease in the
$C_{d l}$ is due to the adsorption of HCL solution inhibitors to the steel surface. The distinction between HMP and PMP inhibitory effectiveness could be explained by the nature of the inhibitor structure. Hence, PMP's efficacy is due to the p-phenyl group's electron delocalization. The $(E I S)$ results of these capacitive loops are simulated by the equivalent circuit shown in Fig.5. In the equivalent circuit, $\mathrm{R}_{\mathrm{s}}$ is the electrolyte resistance, $R_{t}$ the charge transfer resistance and $C_{d l}$ is the double layer capacitance ${ }^{36}$.

Table 3. Characteristic parameters evaluated from the impedance diagram for steel in $1 \mathrm{M} \mathrm{HCl}$ at various concentrations of HMP and PMP

\begin{tabular}{|c|c|c|c|c|c|}
\hline Inhibitor & $\mathrm{C}\left(\mathrm{g} . \mathrm{L}^{-1}\right)$ & $\mathrm{R}_{\mathrm{t}}\left(\Omega . \mathrm{cm}^{2}\right)$ & $\mathrm{f}_{\max }(\mathrm{Hz})$ & $\mathrm{C}_{\mathrm{dl}}\left(\mu \mathrm{F} . \mathrm{cm}^{2}\right)$ & $\mathrm{E}_{\mathrm{Rt}}(\%)$ \\
\hline & $\mathrm{Blank}$ & 40.42 & 83.11 & 70.08 & --- \\
\hline \multirow{3}{*}{ HMP } & 0.125 & 88.44 & 63.291 & 60.04 & 54.30 \\
\cline { 2 - 6 } & 0.25 & 167.6 & 15.823 & 40.61 & 75.80 \\
\cline { 2 - 6 } & 0.5 & 247.8 & 15.823 & 28.43 & 83.36 \\
\hline \multirow{3}{*}{ PMP } & 1 & 388.3 & 15.823 & 25.92 & 89.60 \\
\cline { 2 - 6 } & 0.125 & 93.01 & 35.714 & 47.9 & 56.54 \\
\cline { 2 - 6 } & 0.25 & 191.3 & 22.321 & 37.29 & 79.00 \\
\cline { 2 - 6 } & 0.5 & 370.7 & 14.056 & 30.56 & 89.09 \\
\hline
\end{tabular}




\subsection{Weight loss measurement}

The corrosion rate $\left(W_{\text {corr }}\right)$ and the values of inhibition efficiency $\left(E_{w}\right)$ obtained by the Weight-loss method in the absence and in the presence of various concentrations of each inhibitor at different temperatures [298-328 K] in $1 \mathrm{M} \mathrm{HCl}$ solution after $6 \mathrm{~h}$ of immersion are summarized in Table 4.

Table 4. Influence of HMP and PMP concentrations on the steel corrosion in $1 \mathrm{M} \mathrm{HCl}$ at temperatures 298, 308, 318 and $328 \mathrm{~K}$.

\begin{tabular}{|c|c|c|c|c|c|c|c|c|c|c|}
\hline \multirow[t]{3}{*}{ Inhibitor } & \multicolumn{2}{|c|}{ Concentration } & \multicolumn{2}{|c|}{$298 \mathrm{~K}$} & \multicolumn{2}{|c|}{$308 \mathrm{~K}$} & \multicolumn{2}{|c|}{$318 \mathrm{~K}$} & \multicolumn{2}{|c|}{$328 \mathrm{~K}$} \\
\hline & $\mathrm{g} \mathrm{L}^{-1}$ & $\mathrm{mM}$ & $\begin{array}{c}\mathrm{W}_{\text {corr }} \\
\left(\mathrm{mg} \mathrm{cm}^{-2}\right. \\
\left.\mathrm{h}^{-1}\right)\end{array}$ & $\begin{array}{c}\mathrm{E}_{\mathrm{w}} \\
(\%)\end{array}$ & $\begin{array}{c}\mathrm{W}_{\text {corr }} \\
\left(\mathrm{mgcm}^{-2}\right. \\
\left.\mathrm{h}^{-1}\right)\end{array}$ & $\begin{array}{c}\mathrm{E}_{\mathrm{w}} \\
(\%)\end{array}$ & $\begin{array}{c}\mathrm{W}_{\text {corr }} \\
\left(\mathrm{mg} \mathrm{cm}^{-2}\right. \\
\left.\mathrm{h}^{-1}\right)\end{array}$ & $\begin{array}{c}E_{\mathrm{w}} \\
(\%)\end{array}$ & $\begin{array}{c}\mathrm{W}_{\text {corr }} \\
\left(\mathrm{mg} \mathrm{cm}^{-2}\right. \\
\left.\mathrm{h}^{-1}\right)\end{array}$ & $\begin{array}{c}E_{\mathrm{w}} \\
(\%)\end{array}$ \\
\hline & Blank & ---- & 1.032 & ---- & 1.803 & ---- & 3.483 & ---- & 5.883 & --- \\
\hline \multirow{4}{*}{ HMP } & 0.125 & 0,70 & 0.227 & 78 & 0.288 & 84 & 0.418 & 88 & 0.647 & 84 \\
\hline & 0.25 & 1,40 & 0.175 & 83 & 0.198 & 89 & 0.348 & 90 & 0.471 & 92 \\
\hline & 0.5 & 2,81 & 0.134 & 87 & 0.144 & 92 & 0.244 & 93 & 0.353 & 94 \\
\hline & 1 & 5,62 & 0.083 & 92 & 0.108 & 94 & 0.174 & 95 & 0.235 & 96 \\
\hline \multirow{4}{*}{ PMP } & 0.125 & 0,49 & 0.126 & 88 & 0.144 & 92 & 0.244 & 93 & 0.294 & 95 \\
\hline & 0.25 & 0,98 & 0.072 & 93 & 0.126 & 93 & 0.174 & 95 & 0.235 & 96 \\
\hline & 0.5 & 1,97 & 0.052 & 95 & 0.054 & 97 & 0.104 & 97 & 0.176 & 97 \\
\hline & 1 & 3,94 & 0.041 & 96 & 0.045 & 97.5 & 0.070 & 98 & 0.118 & 98 \\
\hline
\end{tabular}

It can be seen in Table 4 that the speed of corrosion decreases gradually, with the increase in the concentration of PMP and HMP compounds leading to an increase in percentage inhibition efficiency $(E \%)$. The values of percentage inhibition efficiencies calculated from the Weight-loss method attainment, limit value $(96 \%, 98 \%)$ when the concentration of inhibitors is $1 \mathrm{~g} / \mathrm{L}$. This increase can be attributed to the strong adsorption of inhibitors resulting in the formation of a protective layer on the steel surface.

Also, we note that the efficiency $\left(E_{w}\right)$ depends on the temperature and increases with the rise of temperature from 298 to $328 \mathrm{~K}$, and when the concentration reached to $1 \mathrm{~g} / \mathrm{L} \mathrm{E}_{\mathrm{w}}$ of $\mathbf{H M P}$ and PMP, respectively, reached a high value of 96 and $98 \%$ in corrosive media at 328. The inhibition is estimated, at some temperature, to be $84 \%$ for HMP, and $95 \%$ for PMP even at very low concentration $(0.125 \mathrm{~g} / \mathrm{L})$ the protection is higher than $90 \%$ for HMP, and $96 \%$ for PMP, which indicates that both HMP and PMP are very good inhibitors for steel in $1 \mathrm{M} \mathrm{HCl}$. The increase in inhibition efficiency with an increase in temperature may be attributed to the increased adsorption of inhibitor molecules from the metal surface and the inhibitory effect of each inhibitor is reinforced at elevated temperature. An increase in inhibition efficiency with increasing inhibitor concentration and increased efficiency with an increase in temperature is suggestive of the chemical adsorption mechanism ${ }^{30}$.

\subsection{Kinetic and Activation parameters}

The influence of temperature on the corrosion rate and behavior of HMP and PMP on the given media has been realized and the obtained data from are used subsequently to estimate energy $\mathrm{E}^{\circ} \mathrm{a}$ entropy $\Delta \mathrm{S}^{\circ} \mathrm{a}$ and enthalpy $\Delta \mathrm{H}^{\circ}$ a of activation using the following equations 5 and $6^{6}$.

$\mathrm{w}=\operatorname{Aexp}\left(-\frac{\mathrm{E}_{\mathrm{a}}^{\circ}}{\mathrm{R} . \mathrm{T}}\right)$

$\mathrm{W}=\frac{\mathrm{R} \cdot \mathrm{T}}{\mathrm{Nh}} \exp \left(\frac{\Delta \mathrm{S}_{\mathrm{a}}^{\circ}}{\mathrm{R}}\right) \cdot \exp \left(-\frac{\Delta \mathrm{H}^{\circ} \mathrm{a}}{\mathrm{R} \cdot \mathrm{T}}\right)$

where $E^{\circ} a$ is the apparent activation corrosion energy, $\mathrm{T}$ is the absolute temperature, $R$ is the universal gas constant, $A$ is the Arrhenius pre-exponential factor, $\mathrm{h}$ is he Plank's constant. $\mathrm{N}$ is the Avogadro's number, $\Delta S^{\circ} a$ is the entropy of activation and $\Delta H^{\circ} a$ is the enthalpy of activation.

The activation energies are deduced from the slope $\left(-\mathrm{E}^{\circ}{ }_{\mathrm{a}} / \mathrm{R}\right)$ of the corrosion rate logarithm $(w)$ versus the absolute reciprocal temperature (Fig.6) and their values are displayed as Table 5. Use Eq.2 further, plots of $\mathrm{Ln}\left(\mathrm{W} / \mathrm{T}\right.$ ) versus $10^{3} / \mathrm{T}$ (Fig.7) provided straight lines with slopes of $\left(-\Delta \mathrm{H}^{\circ} \mathrm{a} / \mathrm{R}\right)$ and intercepts of $\left(\mathrm{Ln}(\mathrm{R} / \mathrm{Nh})+\left(\Delta \mathrm{S}^{\circ} \mathrm{a} / \mathrm{R}\right)\right)$ from which the values of $\Delta \mathrm{H}^{\circ} \mathrm{a}$ and $\Delta \mathrm{S}^{\circ} \mathrm{a}$ were calculated and shown in Table 5. 


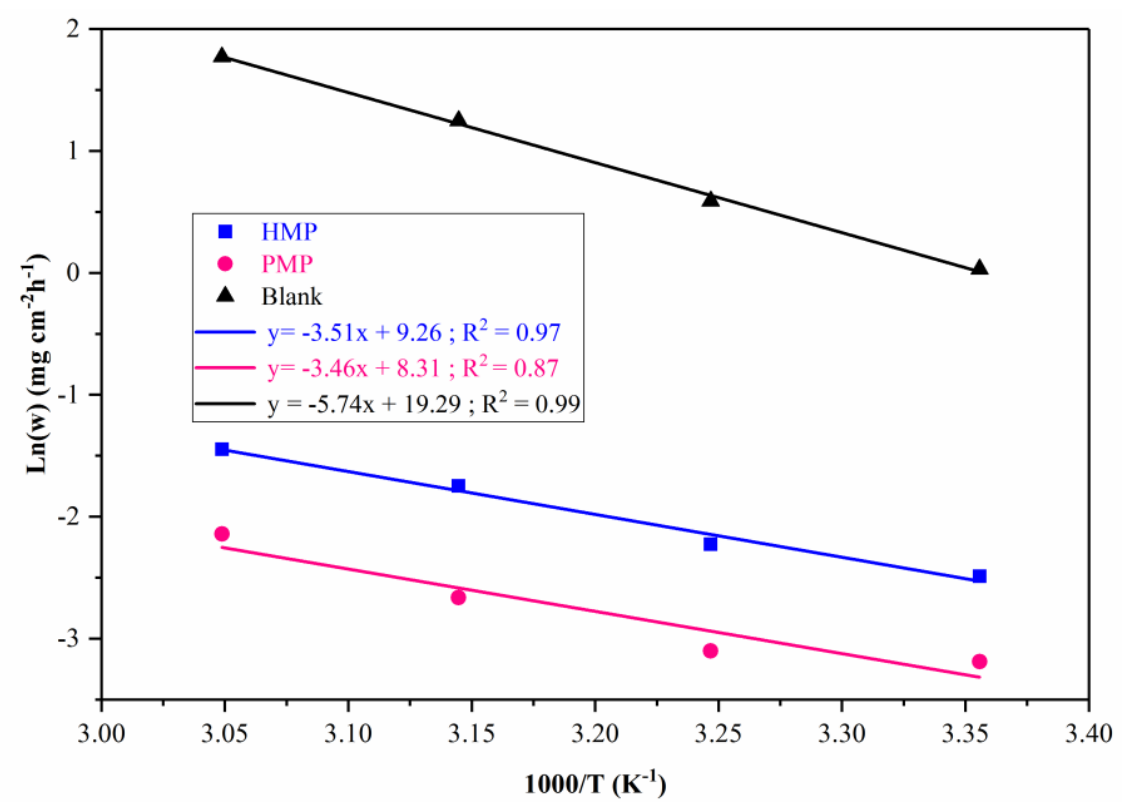

Figure 6. Arrhenius plots for mild steel corrosion rates $(W)$ in $1 \mathrm{M} \mathrm{HCl}$ with and without $1 \mathrm{~g}$. $\mathrm{L}^{-1}$ of $\mathbf{H M P}$ and

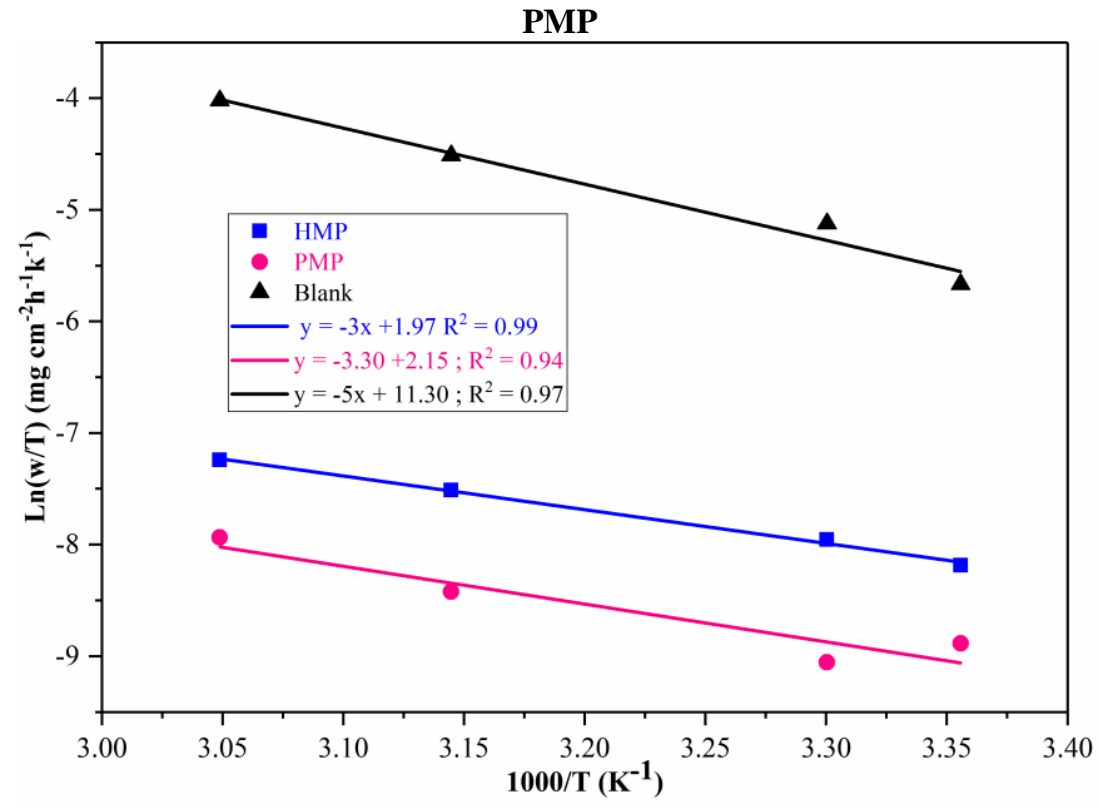

Figure 7. Transition-state plot for mild steel corrosion rates $(W)$ in $1 \mathrm{M} \mathrm{HCl}$ with and without $1 \mathrm{~g}$. $\mathrm{L}^{-1}$ of $\mathbf{H M P}$ and PMP

Table 5. Activation parameters obtained from Weight Loss measurements of HMP and PMP on mild steel in 1 $\mathrm{g} / \mathrm{L}$

\begin{tabular}{|c|c|c|c|}
\hline Inhibitor & $\Delta \mathrm{E}^{\circ}{ }_{\mathrm{a}}\left(\mathrm{kJ} \mathrm{mol}^{-1}\right)$ & $\Delta \mathrm{H}_{\mathrm{a}}^{\circ}\left(\mathrm{kJ} \mathrm{mol}^{-1}\right)$ & $\Delta \mathrm{S}_{\mathrm{a}}^{\circ}\left(\mathrm{J} \mathrm{mol}^{-1} \mathrm{~K}^{-1}\right)$ \\
\hline Blank & 47.76 & 41.60 & -103.67 \\
\hline HMP & 29.20 & 24.96 & -181.29 \\
\hline PMP & 28.79 & 27.71 & -179.80 \\
\hline
\end{tabular}

In the presence of HMP and PMP, the activation energies are lower than those in the uninhibited acid solution (Table 5). Adding inhibitors, therefore, reduces the dissolution of metal in the $1 \mathrm{M} \mathrm{HCl}$ medium ${ }^{37}$. We note that the chemisorption will be the most favorable because of the increase of (Ew) and the lower value of $E^{\circ} a^{38}$. The positive value of enthalpy of activation $\left(\Delta \mathrm{H}^{\circ} \mathrm{a}\right)$ with various concentrations of each inhibitor, meaning that the metal has a low tendency to be dissolved. The negative values of entropy of activation $\left(\Delta \mathrm{S}^{\circ} \mathrm{a}\right)$ are attributed to a reduction in disorder induced by the adsorption of HMP and PMP molecules on the steel surface ${ }^{39}$.

\subsection{Adsorption considerations}


The appropriate isotherm has been obtained by using the values of surface coverage $(\theta)$, evaluated for weight loss measurements. The plot of $C / \theta$ versus $C$ Eq. (7) yields a straight line with all linear correlation coefficients $\left(R^{2}\right)$ is nearly equal to 1 and the slope values are also close to 1 . Thus, the Langmuir model was found to give the best description (Figs.8 9) ${ }^{6}$.

$$
\frac{\mathrm{C}}{\theta}=\frac{1}{\mathrm{~K}}+\mathrm{C}
$$

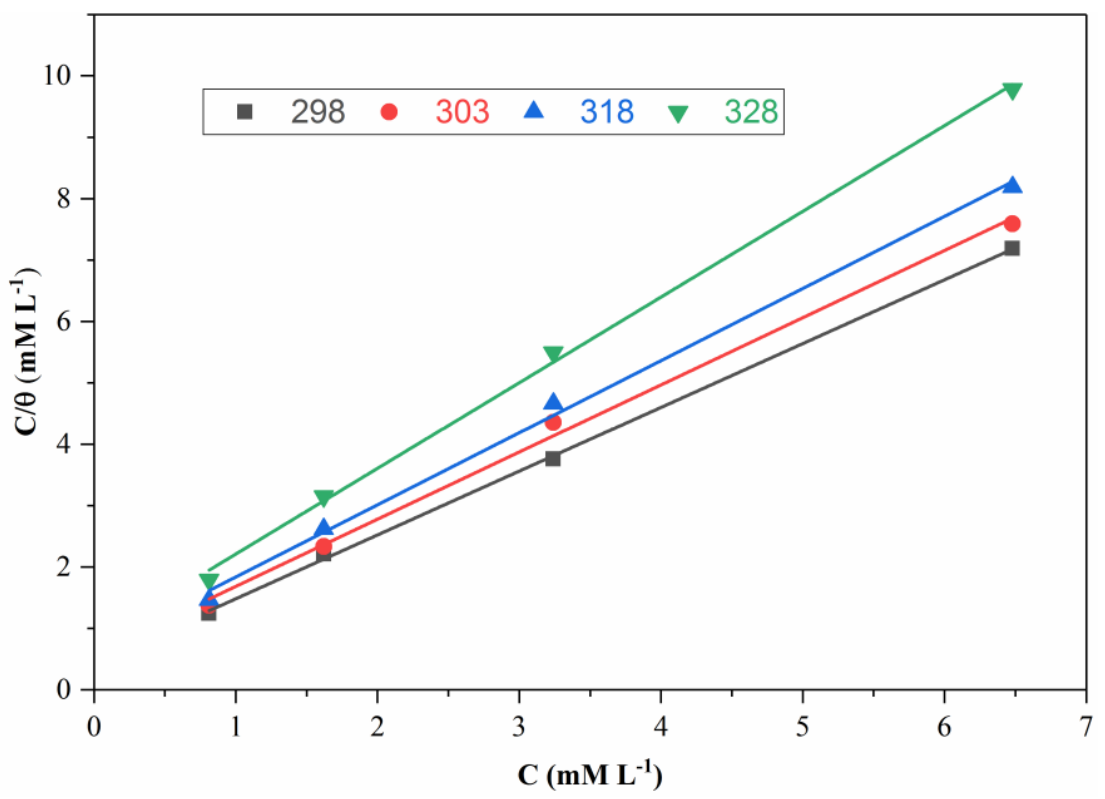

Figure 8. Langmuir adsorption isotherm model for PMP on carbon steel surface at temperatures 298

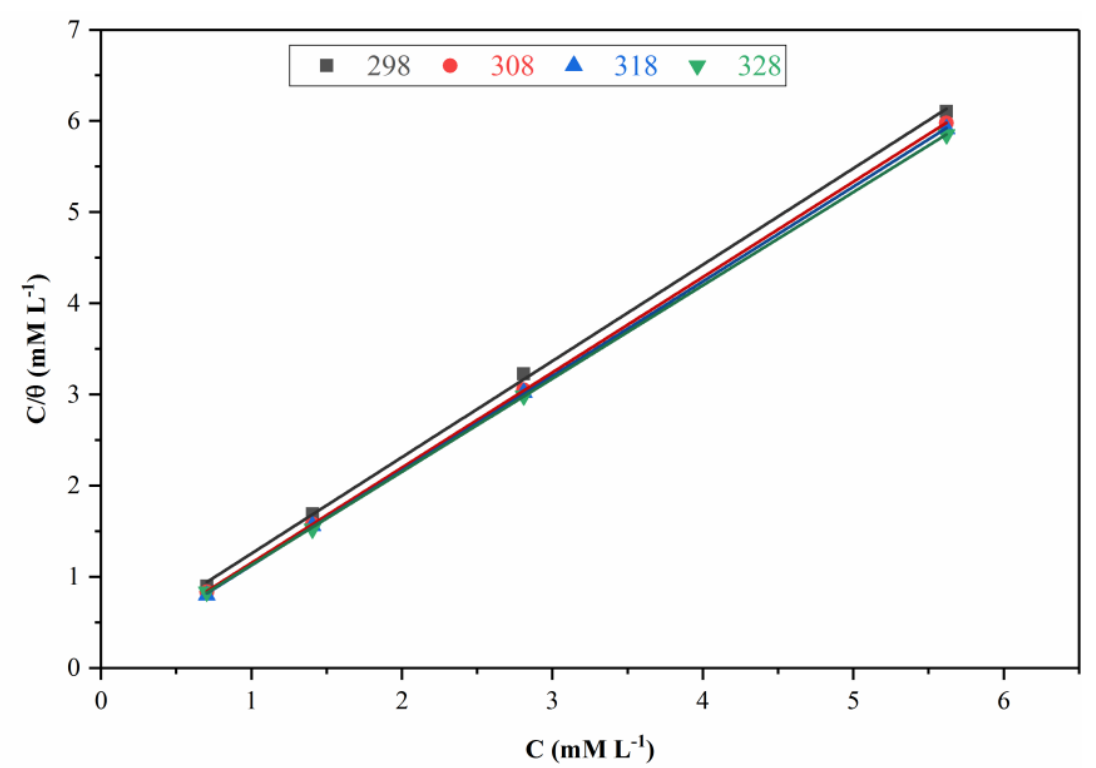

Figure 9. Langmuir adsorption isotherm model for HMP on carbon steel surface at temperatures 298, 308, 318 and $328 \mathrm{~K}$

Table 6. Thermodynamic and equilibrium parameters obtained from weight loss measurements for the adsorption of HMP and PMP on mild steel surface in $1 \mathrm{~g} \mathrm{~L}^{-1}$ at temperatures 298, 308, 318 and $328 \mathrm{~K}$.

\begin{tabular}{|c|c|c|c|c|c|}
\hline Inhibitor & $\mathrm{T}(\mathrm{K})$ & $\mathrm{K}\left(10^{3} \mathrm{~L} \mathrm{~mol}^{-1}\right)$ & $\Delta \mathrm{G}_{\text {ads }}^{\circ}\left(\mathrm{kJ} \mathrm{mol}^{-1}\right)$ & $\Delta \mathrm{H}_{\text {ads }}^{\circ}\left(\mathrm{kJ} \mathrm{mol}^{-1}\right)$ & $\Delta \mathrm{S}_{\text {ads }}^{\circ}\left(\mathrm{J} \mathrm{mol}^{-1} \mathrm{~K}^{-1}\right)$ \\
\hline \multirow[t]{4}{*}{ HMP } & 298 & 7.4 & -32.1 & \multirow[t]{4}{*}{$16.64(\mathrm{Eq}: 5)$} & 163.6 \\
\hline & 308 & 9.3 & -33.7 & & 163.4 \\
\hline & 318 & 11.1 & -35.3 & & 163.3 \\
\hline & 328 & 14.3 & -37.1 & & 166.4 \\
\hline \multirow[t]{4}{*}{ PMP } & 298 & 16.7 & -34.4 & \multirow[t]{4}{*}{24 (Eq: 5) } & 194.9 \\
\hline & 308 & 20.8 & -35.8 & & 194.2 \\
\hline & 318 & 33.3 & -37.5 & & 195.6 \\
\hline & 328 & 40.8 & -40 & & 198.0 \\
\hline
\end{tabular}


It follows from the data presented in Table 6 that the adsorptive equilibrium constant $(\mathrm{K})$ increased with increasing temperature. PMP has a greater value indicating its ability to be absorbed easily and strongly ${ }^{40}$. The equilibrium adsorption constant $\mathrm{K}$ is linked to the standard Gibbs free energy of adsorption $\left(\Delta \mathrm{G}^{\circ}{ }_{\text {ads }}\right)$ with the ensuing equation ${ }^{41}$ :

$\Delta \mathrm{G}^{\circ}{ }_{\text {ads }}=-2.3 \mathrm{RT} \log (55.5 \mathrm{~K})$

The standard adsorption enthalpy $\left(\Delta \mathrm{H}^{\circ}\right.$ ads $)$ could be calculated based on Van't Hoff equation ${ }^{34}$ :

$\operatorname{LnK}=\frac{\Delta \mathrm{H}^{\circ} \text { ads }}{\mathrm{R} . \mathrm{T}}+\mathrm{D}$
Where $\mathrm{R}$ is the universal gas constant, $\mathrm{T}$ is the thermodynamic temperature, $\mathrm{D}$ is integration constant and the value of 55.5 is the concentration of water in the solution in $\mathrm{M}(\mathrm{mol} / \mathrm{L})$.

To calculate the enthalpy of adsorption $\left(\Delta \mathrm{H}^{\circ}\right.$ ads $)$, Ln (K) was plotted against 1/T (Fig.11) and straight-line was obtained with slope equal to $\left(-\Delta \mathrm{H}^{\circ}\right.$ ads $\left./ \mathrm{R}\right)$. With the obtained both parameters of $\Delta \mathrm{G}^{\circ}$ ads and $\Delta \mathrm{H}^{\circ}$ ads, the standard adsorption entropy $\left(\Delta \mathrm{S}^{\circ}\right.$ ads $)$ can be calculated using the following equation. All the standard thermodynamic parameters are listed in Table 6.

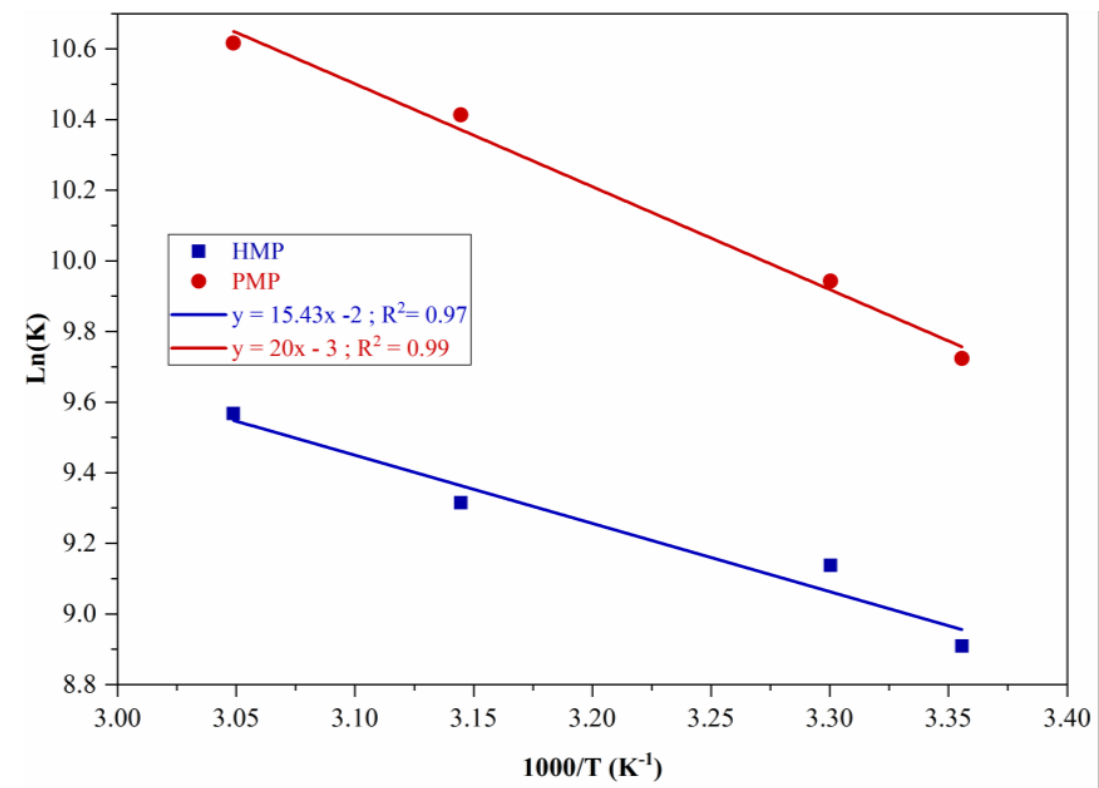

Figure 10. Van't Hoff's plot of Ln K against 1/T for the adsorption of HMP and PMP on to mild steel

$$
\Delta \mathrm{S}_{\text {ads }}^{\circ}=\frac{\Delta \mathrm{H}_{\mathrm{ads}}^{\circ}-\Delta \mathrm{G}_{\mathrm{ads}}^{\circ}}{\mathrm{T}}
$$

The negative values of $\Delta \mathrm{G}^{\circ}$ ads (Table 6) reflected the spontaneous aspect of the inhibitor's adsorption on to the steel surface ${ }^{42}$. Moreover, the values of $\Delta \mathrm{G}^{\circ}$ ads computed as shown in Table 6 were about $-40 \mathrm{KJ}$ $\mathrm{mol}^{-1}$, reflecting that the charge sharing or transfer of the inhibitor to the charged mild steel surface took place (chemisorption) ${ }^{34}$. Moreover, the positive values of $\Delta \mathrm{H}^{\circ}$ ads mean that the dissolution process is an endothermic phenomenon ${ }^{43}$. Finally, the positive value of $\Delta \mathrm{S}^{\circ}$ ads in the presence of inhibitors is an indication of an increase in solvent entropy, because of the adsorption of inhibitors on the metal surface ${ }^{44}$.

\subsection{Calculations of CDFT indices}

This study begins with the optimization of HMP and PMP inhibitors. Certainly, this optimization was confirmed by the presence of zero imaginary frequency in the Hessian matrix ${ }^{45}$. The numbering of the atoms for both inhibitors studied is illustrated in Fig.11. 


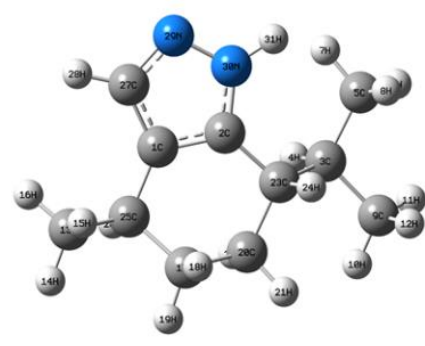

HMP

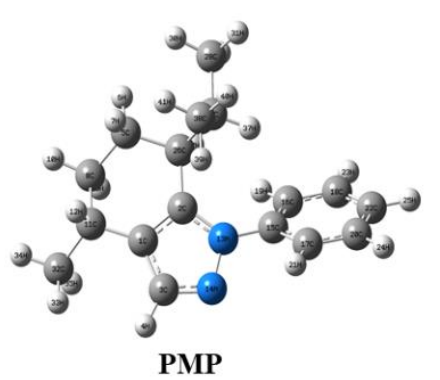

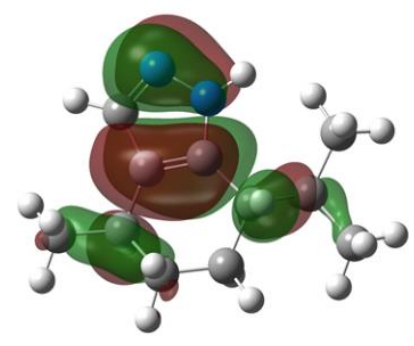

номо

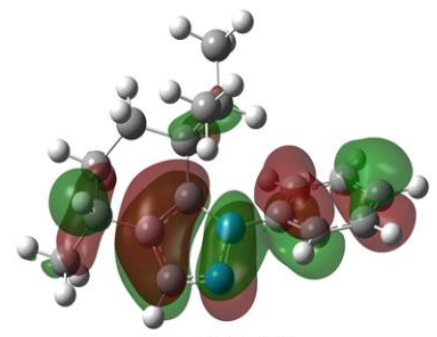

HOMO

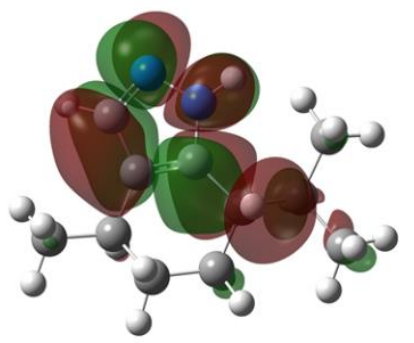

LUMO

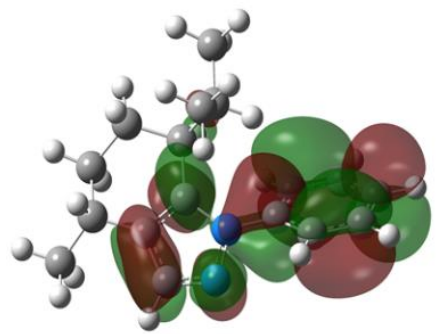

LUMO

Figure 11. The optimized structure and HOMO-LUMO orbitals of HMP and PMP

Several studies devoted to inhibitor corrosion mechanisms have proven that the analysis of the indices defined within the conceptual DFT (CDFT) is a vital role to comprehend corrosion phenomenon. Indeed, a virtuous correlation has been established between the speeds of corrosion and CDFT indices that are frequently associated with the electrondonating ability of the molecule. Additionally, the literature reveals that the adsorption of the inhibitor over the metal surface can proceed with donoracceptor interactions between $\pi$-electrons of the heterocyclic compound and the vacant d-orbital of the metal surface atoms. In this sense, the lower value of the energy gap $\Delta \mathrm{E}\left(\mathrm{E}_{\mathrm{BV}}-\mathrm{E}_{\mathrm{HO}}\right)$ of inhibitor indicates a tendency of this to donate electrons to suitable acceptor metal and consequently facilitate adsorption between inhibitor and metal ${ }^{46,47}$ In order to evaluate the global Electron density transfer from inhibitor via the iron metal certain CDFT indices related to the electronic molecular structure are calculated such as: the electronic, chemical potential $(\mu)$ chemical hardness $(\eta)$ energy gap $(\Delta \mathrm{E})$ between $\mathrm{E}_{\mathrm{BV}}$ and $\mathrm{E}_{\mathrm{HO}}$ the fraction of an electron transferred $(\Delta \mathrm{N})$ and electronegativity $(\chi)$ for HMP and PMP inhibitors (Table 7).

Table 7. The quantum chemical parameters of the studies inhibitors at the DFT method for the neutral form of inhibitors.

\begin{tabular}{|c|c|c|c|c|c|c|c|}
\hline Inhibitor & $\mathbf{E}_{\text {HO }}$ & $\mathbf{E}_{\mathbf{B V}}$ & $\boldsymbol{\mu}$ & $\boldsymbol{\eta}$ & $\Delta \mathbf{E}$ & $\Delta \mathbf{N}$ & $\boldsymbol{\chi}$ \\
\hline HMP & -5.99 & 0.70 & -2.64 & 3.34 & 6.68 & 0.65 & 2.64 \\
\hline PMP & -5.93 & -0.44 & -3.19 & 2.75 & 5.52 & 0.69 & 3.19 \\
\hline
\end{tabular}

The local reactivity of inhibitor is portrayed framework of the nucleophilic $\mathrm{P}^{-}$and electrophilic $\mathrm{P}^{+}$ Parr functions. The utility of these indices focused, in fact, to differentiate each amount of the molecule based on its individual chemical behavior due to different substituent functional groups. Thus, the site for nucleophilic attack will be the place where the value of $\mathrm{P}+$ is a maximum. In turn, the site for an electrophilic attack is explained by the maximum value of $\mathrm{P}^{-}$. Nucleophilic $\mathrm{P}^{-}$and electrophilic $\mathrm{P}^{+}$Parr functions for the significant atoms of HMP and PMP inhibitors are reported in Table 8.

Table 8. Nucleophilic $\mathrm{P}^{-}$and electrophilic $\mathrm{P}^{+}$Parr functions for the significant atoms of $\mathbf{H M P}$ and PMP inhibitors.

\begin{tabular}{|c|c|c|c|c|c|c|c|c|}
\hline \multirow{2}{*}{ Number } & \multicolumn{3}{|c|}{ HMP } & & Number & \multicolumn{3}{|c|}{ PMP } \\
\cline { 2 - 5 } \cline { 6 - 8 } & Atom & $\mathrm{P}^{-}$ & $\mathrm{P}^{+}$ & & & Atom & $\mathrm{P}^{-}$ & $\mathrm{P}^{+}$ \\
\hline 1 & $\mathrm{C}$ & 0.399 & -0.007 & & 1 & $\mathrm{C}$ & 0.402 & 0.008 \\
\hline 2 & $\mathrm{C}$ & 0.335 & 0.310 & & 2 & $\mathrm{C}$ & -0.064 & 0.163 \\
\hline 3 & $\mathrm{C}$ & 0.029 & 0.007 & & 3 & $\mathrm{C}$ & 0.041 & 0.029 \\
\hline 17 & $\mathrm{C}$ & 0.013 & -0.001 & & 13 & $\mathrm{~N}$ & 0.184 & -0.018 \\
\hline 29 & $\mathrm{~N}$ & 0.360 & 0.277 & & 14 & $\mathrm{~N}$ & 0.072 & 0.134 \\
\hline
\end{tabular}




\begin{tabular}{|l|l|l|l|l|l|l|l|l|}
\hline 30 & $\mathrm{~N}$ & -0.058 & 0.182 & & 15 & $\mathrm{C}$ & 0.072 & 0.244 \\
\hline 24 & $\mathrm{H}$ & 0.033 & 0.310 & & 16 & $\mathrm{C}$ & 0.065 & 0.121 \\
\hline$* *$ & $* *$ & $* * * *$ & $* * * *$ & & 17 & $\mathrm{C}$ & 0.080 & 0.042 \\
\hline$* *$ & $* *$ & $* * * *$ & $* * * *$ & & 22 & $\mathrm{C}$ & 0.175 & 0.309 \\
\hline
\end{tabular}

From Table 7 we noticed that the HMP and PMP inhibitors have a positive value of $\Delta \mathrm{N}$ indicates clearly the capability of the inhibitor to donate its electrons to iron metal. As well it is possible to observe that the chemical hardness and the energy gap of PMP inhibitor have lower values than that of HMP; and that the PMP has a higher fraction of transferred electrons than that of HMP. These results point out that the inhibiting efficiency order for the HMP and PMP inhibitors is the following: PMP > HMP in accordance with the experience.

As depicted in Table 8, for the nucleophilic attack, the most reactive site related to PMP is on the carbon atoms (C2, C15, C16, and C22) and nitrogen atom N14, HMP is on carbon atom C2, nitrogen atoms (N29 and N30) and a hydrogen atom H24. Besides, for the electrophilic attack, the preferred reactive site associated with PMP is the follow atoms category: carbon atoms ( $\mathrm{C} 1$ and $\mathrm{C} 22)$ and nitrogen atom N13, HMP is on carbon atoms ( $\mathrm{C} 1$ and $\mathrm{C} 2)$ and nitrogen atom $\mathrm{N} 29$. This result displays that the two inhibitors studied have the capability to react locally with the iron metal either by a donor or acceptor character.

\subsection{Monte Carlo simulation (MC)}

Molecular Simulation was conducted to investigate the relationship between both PMP and HMP inhibitors and the metal surface involved. Before this analysis, it is also possible to obtain the radial distribution function (RDF) (or pair correlation function) $g(r)$. The R D F is used as a technique for learning the connection length. Modern researchers suggested that the appearance of peaks from $1 \AA$ to $3.5 \AA$ (Fig.12) is a sign of tiny chemisorption-related bonds ${ }^{47}$. The findings achieved to strengthen the maximum adsorption ability of the compound inhibitors of Menthopyrazole tested to safeguard metal from dissolution. Because of their higher capacity to switch electrons through these active locations to the metal surface. The interaction energy between the molecule of the inhibitor and the surface of $\mathrm{Fe}$ (110) was acquired using $\mathrm{Eq}(7)^{48}$.

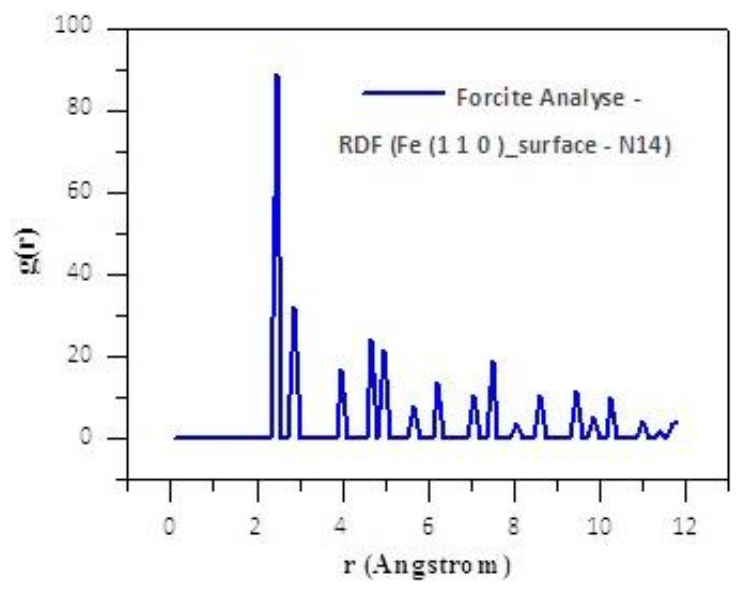

Figure.12 Radial distribution function of the PMP on the Fe (110) surface in solution

$\mathrm{E}_{\text {ads }}=\mathrm{E}_{\text {total }}+\mathrm{E}_{\text {sol }}-\left(\mathrm{E}_{\text {surface+sol }}+\mathrm{E}_{\text {inhibitor+sol }}\right)$

$\left(\mathrm{E}_{\mathrm{ads}}=\mathrm{E}\right.$ adsorption; $\mathrm{E}_{\mathrm{sol}}=\mathrm{E}$ solution $)$

Where $E_{\text {total }}, E_{\text {surface+solution, }} E_{\text {inhibitor+solution, and }} E_{\text {solution }}$ correspond respectively to the total energies of the $\mathrm{Fe}$ (110) surface with adsorbed inhibitor and solution, the total energy of the surface and solution, the total energy of the system except the iron crystal, and the total energy of the solution.

The outputs and descriptors calculated by the Monte Carlo simulation in two phases including the total adsorption (Eads) rigid adsorption (ERA) and deformation energies (Edef) are presented in Table 9.

Table 9. Outputs and descriptors calculated by the Monte Carlo simulation for adsorption of HMP and PMP on Fe (110) (in kcal.mol ${ }^{-1}$ ).

\begin{tabular}{|c|c|c|c|c|c|c|}
\hline Molecule & Phase & $\mathrm{E}_{\text {tot }}$ & $\mathrm{E}_{\mathrm{ads}}$ & ERA & Edef & $\mathrm{dEads} / \mathrm{dNi}$ \\
\hline \multirow{2}{*}{ HMP } & $\mathrm{G}$ & -66.87 & -73.57 & -74.35 & 0.78 & -73.57 \\
\cline { 2 - 7 } & $\mathrm{A}$ & -5186.17 & -5192.87 & -5467.62 & 274.75 & -80.70 \\
\hline \multirow{2}{*}{ PMP } & $\mathrm{G}$ & -85.47 & -165.85 & -139.04 & -26.81 & -165.85 \\
\cline { 2 - 7 } & $\mathrm{A}$ & -6586.89 & -6667.27 & -6995.73 & 328.46 & -148.46 \\
\hline
\end{tabular}

In Table 9, it can be noted that the adsorption energy of the inhibitors is negative in each case. This means that the adsorption on the surfaces of both inhibitors is spontaneous and that the interaction between them will take place in aqueous and gas phases ${ }^{49,6}$. The adsorption energies of the molecules studied improved in the order of HMP < PMP and this latter molecule gave the highest adverse energy of adsorption. This indicates that PMP had better efficiency in inhibition than HMP. These findings, therefore, corroborate the similarities in electronic and molecular parameters derived from quantum 
chemical computations. Furthermore, as can be seen from the elevated absolute value of $\mathrm{dE}_{\mathrm{ad}} / \mathrm{dNi}$ for molecules studied in Table 9, inhibitor molecules substitute $\mathrm{H}_{2} \mathrm{O}$ on the iron surface resulting in the creation of inhibitor molecules protective film. The experimentally observed elevated inhibition impact could lead from the strong interaction between inhibitors and metallic surface. Their adsorption on the iron surface offers a bigger blocking region on the steel surface and avoids possible acidic attacks on it ${ }^{30}$. Figures 13 and 14 show the close connections between the tested molecules and the surface of the Fe (1 110$)$ as well as the best adsorption configuration for these compounds in gaseous and aqueous stages.

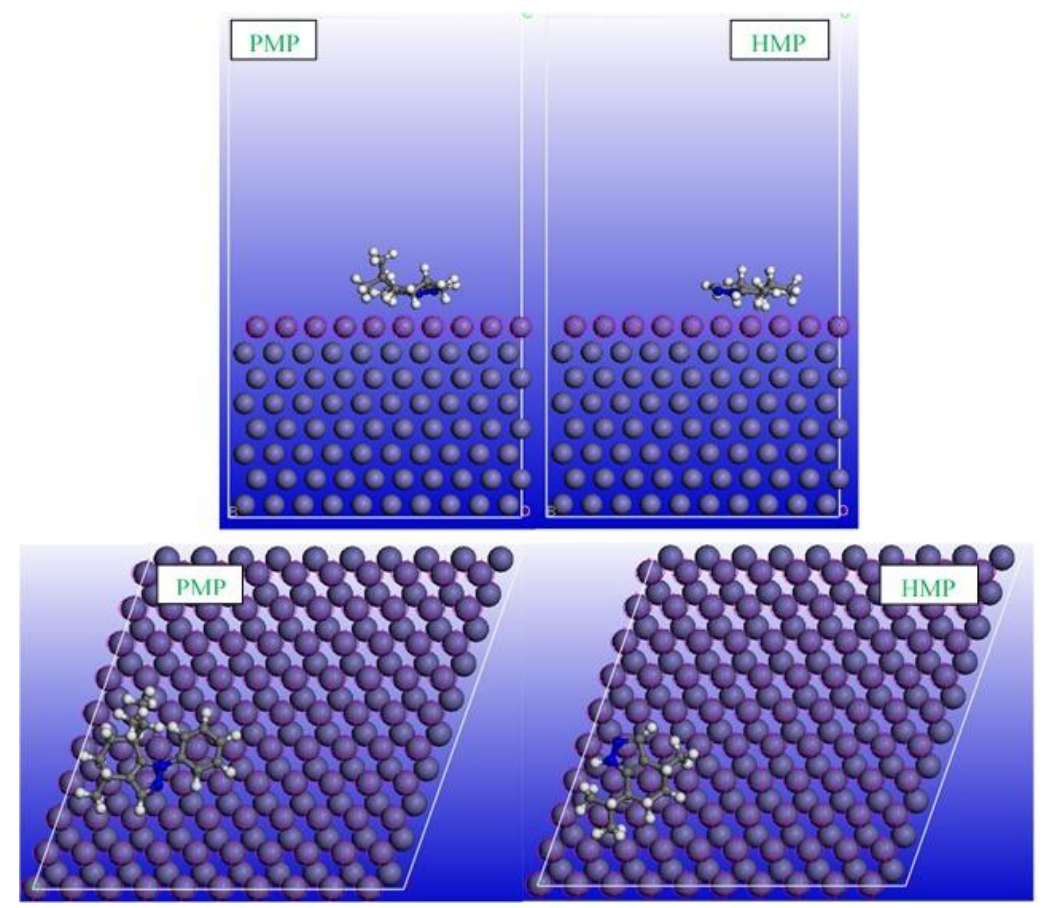

Figure.13 Side and top views of the stable adsorption configuration for Fe (110)/PMP and HMP /500 $\mathrm{H}_{2} \mathrm{O}$ system obtained using the adsorption locator module
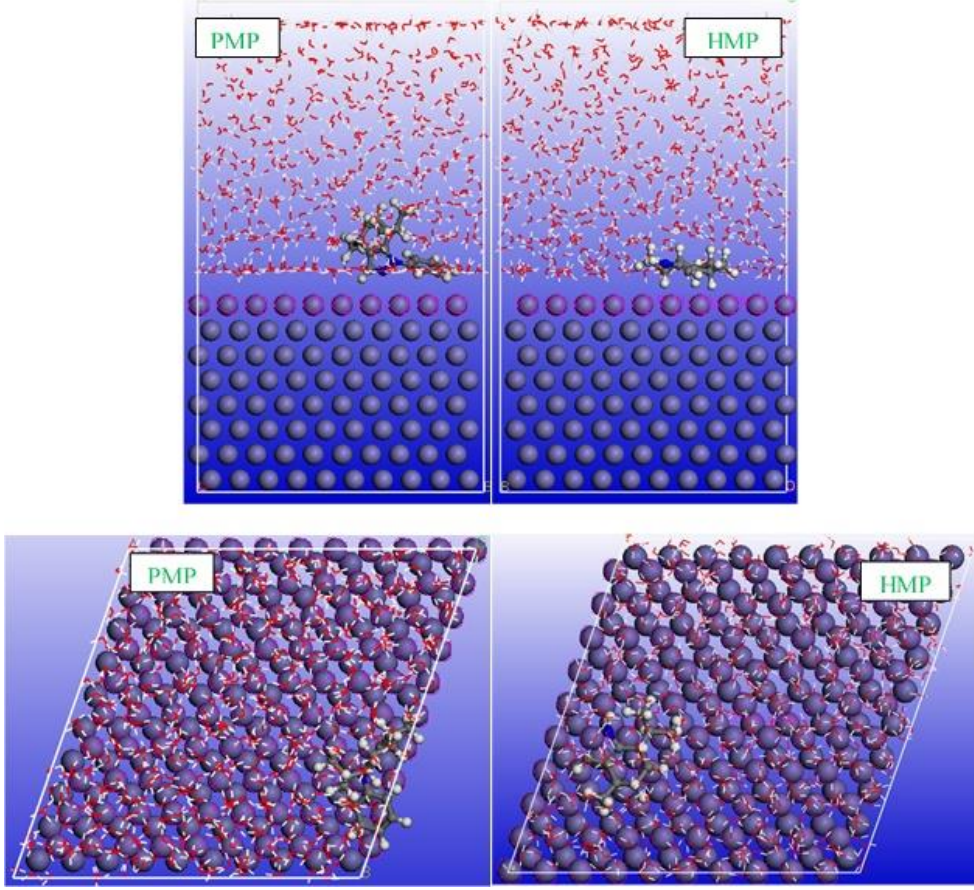

Figure 14. Side and top views of the stable adsorption configuration for Fe (110)/PMP and HMP obtained using the adsorption locator module

\section{Conclusion}

The corrosion inhibition effect of two new menthone derivatives such as menthopyrazole (HMP) and 1-phenylmenthopyrazole (PMP) on corrosion of mild steel in $1 \mathrm{M} \mathrm{H} \mathrm{Cl}$ has been investigated using weight loss and electrochemical measurement in addition to 
quantum chemical calculations including density functional and Monte Carlo simulation.

Frome the overall experimental results obtained we can deduct that HMP and PMP act as good inhibitors for the corrosion of steel in $\mathrm{HCl}$ medium. Note that the inhibition efficiency increases in both the concentration and the temperature of the new synthesized inhibitors to attain $98 \%$ for PMP at $1 \mathrm{~g} / \mathrm{L}$. Also, the polarization curves revealed that the used inhibitors were mixed-type inhibitors. In addition to this, the adsorption of use compounds on the mild steel surface obeyed a Langmuir isotherm. A good correlation was found between the inhibition efficiency and quantum chemical parameters ( $\mathrm{E}_{\text {Hомо }}$. $\mathrm{E}_{\text {LUMO }}$ and gap energy $(\Delta \mathrm{E})$. This result is in good agreement with experimental results. Finally, MDS suggests that the strongest interaction of both inhibitors PMP and HMP with the metallic surface can be adsorbed on Fe ( $\left.\begin{array}{lll}1 & 1 & 0\end{array}\right)$ in near flat orientation mainly though the pyrazole and phenyl rings. Note that in aqueous phase, especially for PMP some distortions have been observed with higher adsorption energies.

\section{References}

1- M.A. Bedair, S.A. Soliman, M.A. Hegazy, I.B. Obot, A.S. Ahmed, Empirical and theoretical investigations on the corrosion inhibition characteristics of mild steel by three new Schiff base derivatives, Journal of Adhesion Science and Technology, 2019, 33,1139-1168.

2- A.K. Singh, S. Thakur, B. Pani, B. Chugh, H. Lgaz, I.-M. Chung, P. Chaubey, A.K. Pandey, J. Singh, Solvent-free microwave assisted synthesis and corrosion inhibition study of a series of hydrazones derived from thiophene derivatives: Experimental, surface and theoretical study, Journal of Molecular Liquids, 2019, 283, 788-803.

3- J. Zhang, 2-(3H-Imidazol-4-yl)-ethylamine as a Green Corrosion Inhibitor for Q235 Steel in Hydrochloric Acid, Int. J. Electrochem. Sci., 2020, 15, 1437-1449.

4- A. Singh, K.R. Ansari, M.A. Quraishi, S. Kaya, Theoretically and experimentally exploring the corrosion inhibition of N80 steel by pyrazol derivatives in simulated acidizing environment, Journal of Molecular Structure, 2020, 127685.

5- R.A. Rikkouh, T. Douadi, H. Hamani, M. AlNoaimi, S. Chafaa, Inhibition effect of 4, 4'-thio bis $\$\{\$ N-[(E)-p h e n o l-3-y l m e t h y l i d e n e]$ aniline $\$\}$ on the corrosion of mild steel in $\mathrm{HCl}$ solution under stagnant condition and hydrodynamic flow, Journal of Adhesion Science and Technology, 2020, 1-26.

6- Z. Rouifi, M. Rbaa, A.S. Abousalem, F. Benhiba, T. Laabaissi, H. Oudda, B. Lakhrissi, A. Guenbour, I. Warad, A. Zarrouk, Synthesis, Characterization and Corrosion Inhibition Potential of Newly Benzimidazole Derivatives:
Combining Theoretical and Experimental Study, Surfaces and Interfaces. 2020, 100442.

7- J. Zhang, 2-(3H-Imidazol-4-yl)-ethylamine as a Green Corrosion Inhibitor for Q235 Steel in Hydrochloric Acid, Int. J. Electrochem. Sci., 2020, 15, 1437-1449.

8- E.K. Ardakani, E. Kowsari, A. Ehsani, Imidazolium-derived polymeric ionic liquid as a green inhibitor for corrosion inhibition of mild steel in $1.0 \mathrm{M} \mathrm{HCl}$ : Experimental and computational study, Colloids and Surfaces A: Physicochemical and Engineering Aspects, 2020, 586, 124195.

9- A. Sedik, D. Lerari, A. Salci, S. Athmani, K. Bachari, İ. Gecibesler, R. Solmaz, Dardagan Fruit extract as eco-friendly corrosion inhibitor for mild steel in $1 \mathrm{M} \mathrm{HCl}$ : Electrochemical and surface morphological studies, Journal of the Taiwan Institute of Chemical Engineers, 2020. https://doi.org/10.1016/j.jtice.2019.12.006

10-Z. Faska, A. Bellioua, M. Bouklah, L. Majidi, R. Fihi, A. Bouyanzer, B. Hammouti, Effect of pulegone and pulegone oxide on the corrosion of steel in $1 \mathrm{M} \mathrm{HCl}$, Monatshefte Für ChemieChemical Monthly, 2008, 139, 1417-1422.

11-L. Majidi, Z. Faska, M. Znini, S. Kharchouf, A. Bouyanzer, B. Hammouti, Synthesis and anticorrosive effects of epoxy-allylpulegols on steel in molar hydrochloric acid, J. Mater. Environ. Sci., 2010, 1, 219-226.

12-S. Kharchouf, L. Majidi, M. Znini, J. Costa, B. Hammouti, J. Paolini, Stereoselective synthesis and corrosion inhibition behaviour of Allyldihydrocarveols on steel in molar hydrochloric acid, Int. J. Electrochem. Sci., 2012, 7, 10325-10337.

13-S. Kharchouf, L. Majidi, M. Bouklah, B. Hammouti, A. Bouyanzer, A. Aouniti, Effect of three 2-allyl-p-mentha-6, 8-dien-2-ols on inhibition of mild steel corrosion in $1 \mathrm{M} \mathrm{HCl}$, Arabian Journal of Chemistry, 2014, 7, 680-686.

14-A. Ansari, M. Znini, I. Hamdani, L. Majidi, A. Bouyanzer, B. Hammouti, Experimental and theoretical investigations anti-corrosive properties of Menthone on mild steel corrosion in hydrochloric acid, J. Mater. Environ. Sci., 2014, 5, 81-94.

15-Á. Nagy, Density functional. Theory and application to atoms and molecules, Physics Reports, 1998, 298, 1-79.

16-C. Lee, W. Yang, R.G. Parr, Development of the Colle-Salvetti correlation-energy formula into a functional of the electron density, Physical Review B, 1988, 37, 785.

17-W.J. Hehre, L. Radom, P. Schleyer, v. R. Pople, JA Ab initio molecular orbital theory, Wiley: New York, 1986.

18-A. Ansari, A. Oubair, M. Znini, Synthesis and Characterization of new Menthopyrazole Compounds derived from Menthone, International Journal of Innovation and Applied Studies, 2018, 24, 1819-1822. 
19-R.A. Rikkouh, T. Douadi, H. Hamani, M. Al-Noaimi, S. Chafaa, Inhibition effect of 4,4'-thio bis N-[(E)-phenol-3-ylmethylidene] aniline on the corrosion of mild steel in $\mathrm{HCl}$ solution under stagnant condition and hydrodynamic flow, Journal of Adhesion Science and Technology, 2020, 1-26.

20-P. Hohenberg, W. Kohn, Density Functional Theory (DFT), Phys. Rev., 1964, 136, B864.

21-I.B. Obot, D.D. Macdonald, Z.M. Gasem, Density functional theory (DFT) as a powerful tool for designing new organic corrosion inhibitors. Part 1: an overview, Corrosion Science, 2015, 99, 1-30.

22-M. Frisch, G.W. Trucks, H.B. Schlegel, G.E. Scuseria, M.A. Robb, J.R. Cheeseman, G. Scalmani, V. Barone, B. Mennucci, Ga. Petersson, Gaussian 09, revision a. 02, gaussian, Inc., Wallingford, CT., 2009, 200, 28.

23-R.G. Parr, W. Yang, Density Functional Theory of Atoms and Molecules, New York: Oxford Univ, Press, 1989.

24-L.R. Domingo, P. Pérez, J.A. Sáez, Understanding the local reactivity in polar organic reactions through electrophilic and nucleophilic Parr functions, RSC Advances, 2013, 3 ,1486-1494.

25-C. Verma, H. Lgaz, D.K. Verma, E.E. Ebenso, I. Bahadur, M.A. Quraishi, Molecular dynamics and Monte Carlo simulations as powerful tools for study of interfacial adsorption behavior of corrosion inhibitors in aqueous phase: a review, Journal of Molecular Liquids, 2018, 260, 99-120.

26-M.A. Bedair, The effect of structure parameters on the corrosion inhibition effect of some heterocyclic nitrogen organic compounds, Journal of Molecular Liquids, 2016, 219, 128-141.

27-Accelrys Inc., Materials Studio Revision 8.0. San Diego USA (2016), 2016.

28-H. Sun, COMPASS: an ab initio force-field optimized for condensed-phase applications overview with details on alkane and benzene compounds, The Journal of Physical Chemistry B, 1998, 102, 7338-7364.

29-L. Afia, O. Hamed, M. Larouj, H. Lgaz, S. Jodeh, R. Salghi, Novel natural based diazepines as effective corrosion inhibitors for carbon steel in $\mathrm{HCl}$ solution: experimental, theoretical and Monte Carlo simulations, Transactions of the Indian Institute of Metals, 2017, 70, 2319-2333.

30-A.E.-A.S. Fouda, M.A. Ismail, A.A. Al-Khamri, A.S. Abousalem, Experimental, quantum chemical and molecular dynamic studies on the action of arylthiophene derivatives as acid corrosion inhibitors, Journal of Molecular Liquids, 2019, 111178.

31-G. Mouhsine, K. Tarfaoui, M. Ouakki, M. Nehiri, M.E. Touhami, N. Barhada, M. Ouhssine, Valorization of the essential oil of Zingiber officinale by its Use as inhibitor against the corrosion of the carbon steel in acid medium hydrochloric acid 1M, Mediterranean Journal of Chemistry, 2019, 8, 17-24.

32-A.K. Satapathy, G. Gunasekaran, S.C. Sahoo, K. Amit, P.V. Rodrigues, Corrosion inhibition by Justicia gendarussa plant extract in hydrochloric acid solution, Corrosion Science, 2009, 51, 2848-2856.

33-A.A. Ganash, Comparative Evaluation of Anticorrosive Properties of Mahaleb Seed Extract on Carbon Steel in Two Acidic Solutions, Materials, 2019, 12, 3013.

34-S. Shahabi, S. Hamidi, J.B. Ghasemi, P. Norouzi, A. Shakeri, Synthesis, experimental, quantum chemical and molecular dynamics study of carbon steel corrosion inhibition effect of two Schiff bases in $\mathrm{HCl}$ solution, Journal of Molecular Liquids, 2019, 285, 626-639.

35-F. Mansfeld, M.W. Kendig, S. Tsai, Evaluation of corrosion behavior of coated metals with AC impedance measurements, Corrosion, 1982, 38, 478-485.

36-M. Benabdellah, A. Aouniti, A. Dafali, B. Hammouti, M. Benkaddour, A. Yahyi, A. Ettouhami, Investigation of the inhibitive effect of triphenyltin 2-thiophene carboxylate on corrosion of steel in $2 \mathrm{M} \mathrm{H}_{3} \mathrm{PO}_{4}$ solutions, Applied Surface Science, 2006, 252, 8341-8347.

37-G.-N. Mu, X.-H. Li, Q. Qu, J. Zhou, Synergistic effect on corrosion inhibition by cerium (IV) ion and sodium molybdate for cold rolled steel in hydrochloric acid solution, Acta Chim. Sin., 2004, 62, 2386-2390.

38-A.M. Badiea, K.N. Mohana, Effect of temperature and fluid velocity on corrosion mechanism of low carbon steel in presence of 2-hydrazino-4, 7-dimethylbenzothiazole in industrial water medium, Corrosion Science, 2009, 51, 2231-2241.

39-S. Sankarapapavinasam, M.F. Ahmed, Benzenethiols as inhibitors for the corrosion of copper, Journal of Applied Electrochemistry, 1992, 22, 390-395.

40-L. Tang, G. Mu, G. Liu, The effect of neutral red on the corrosion inhibition of cold rolled steel in 1.0 M hydrochloric acid, Corrosion Science, 2003, 45, 2251-2262.

41-M. Murmu, S.K. Saha, N.C. Murmu, P. Banerjee, Effect of stereochemical conformation into the corrosion inhibitive behaviour of double azomethine based Schiff bases on mild steel surface in $1 \mathrm{~mol} \mathrm{~L}-1 \mathrm{HCl}$ medium: An experimental, density functional theory and molecular dynamics simulation study, Corrosion Science, 2019, 146, 134-151.

42-A.K. Singh, A.K. Pandey, P. Banerjee, S.K. Saha, B. Chugh, S. Thakur, B. Pani, P. Chaubey, G. Singh, Eco-friendly disposal of expired antituberculosis drug isoniazid and its role in the protection of metal, Journal of Environmental Chemical Engineering, 2019, 7, 102971.

43-M.A. Hegazy, H.M. Ahmed, A.S. El-Tabei, Investigation of the inhibitive effect of 
p-substituted 4-(N, N, N-dimethyldodecylammonium bromide) benzylidene-benzene-2-ylamine on corrosion of carbon steel pipelines in acidic medium, Corrosion Science, 2011, 53, 671-678.

44-R. Hsissou, S. Abbout, A. Berisha, M. Berradi, M. Assouag, N. Hajjaji, A. Elharfi, Experimental, DFT and molecular dynamics simulation on the inhibition performance of the DGDCBA epoxy polymer against the corrosion of the E24 carbon steel in $1.0 \mathrm{M} \mathrm{HCl}$ solution, Journal of Molecular Structure, 2019, 1182, 340-351.

45-C. Gonzalez, H.B. Schlegel, Improved algorithms for reaction path following: Higher-order implicit algorithms, The Journal of Chemical Physics, 1991, 95, 5853-5860.

46-C. Öğretir, B. Mihci, G. Bereket, Quantum chemical studies of some pyridine derivatives as corrosion inhibitors, Journal of Molecular Structure: Theochem., 1999, 488, 223-231.
47-I. Lukovits, E. Kalman, F. Zucchi, Corrosion inhibitors - correlation between electronic structure and efficiency, Corrosion, 2001, 57, 3-8.

48-S.K. Saha, A. Dutta, P. Ghosh, D. Sukul, P. Banerjee, Adsorption and corrosion inhibition effect of Schiff base molecules on the mild steel surface in $1 \mathrm{M} \mathrm{HCl}$ medium: a combined experimental and theoretical approach, Physical Chemistry Chemical Physics, 2015, 17, 5679-5690.

49-R. Hsissou, S. Abbout, R. Seghiri, M. Rehioui, A. Berisha, H. Erramli, M. Assouag, A. Elharfi, Evaluation of corrosion inhibition performance of phosphorus polymer for carbon steel in [1 M] $\mathrm{HCl}$ : Computational studies (DFT, MC and MD simulations), Journal of Materials Research and Technology, 2020. https://doi.org/10.1016/j.jmrt.2020.01.002. 